\title{
Geometrical illusions in solid objects under ordinary viewing conditions
}

\author{
PATRICIA R. DELUCIA and JULIAN HOCHBERG \\ Columbia University, New York, New York
}

\begin{abstract}
The Müller-Lyer and Ponzo illusions were obtained under free binocular viewing of threedimensional objects, and the function relating magnitude of illusion to fin angle, characteristic of converging-line versions of the Müller-Lyer pattern, was closely paralleled by volumetric (threecone), line-free objects (but not with an erect, planar "walk-through" construction and moving observers). Illusions cannot be dismissed as artifacts of static, impoverished viewing, therefore, but must be explained within any general theory of perception. Perspective explanations have difficulties with such three-dimensional manifestations, and seem completely inapplicable to our further finding that approximately the same amount of illusion occurred in objects and patterns with no oblique lines or edges. Confusion or averaging theories, not themselves tested here, re main unthreatened by these data.
\end{abstract}

The visual illusions, often considered tools for testing perceptual theories (Gregory, 1966; Tolman \& Brunswik, 1935; Woodworth, 1938), have also been held to occur only in the case of artificial and impoverished stimulation and to be therefore irrelevant to our understanding of ordinary perception (Gibson, 1950, 1966, 1979; Michaels \& Carello, 1981; Pieron, 1955, cited in Fisher \& Lucas, 1969). ${ }^{1}$ But the assertion that illusions occur only in simple line drawings or line-like wire forms, and not in the perception of real objects and events, is not based on any data; it rests solely on the plausible premise that evolution should provide us with perceptual systems that, under ordinary viewing conditions, correctly extract the information that specifies the objects and events in the world.

Evidence contradicts this argument. We note, first, that even if illusions occur only in artificial situations, we must nevertheless undertake to study them, because humans live increasingly in an artificial world and are dependent on two-dimensional displays. (See Fisher \& Lucas, 1969, for anecdotes and data concerning air-traffic control, pilot error, etc.; Beaty, 1969, and Gillingham \& Wolfe, 1985, for airborne illusions; DeLucia, 1991, for size/distance illusions in computer-generated images of objects moving in depth; and Chadwick, 1976, for errors that geologists make in reading striated rock formations.)

This research was partially supported by National Science Foundation Grant BSN-8209470 to Julian Hochberg. Final preparation of this article was completed while Patricia R. DeLucia held a National Research Council (USAF Armstrong Laboratory) Research Associateship. We thank Raymond Baeza for constructing the solid cone Müller-Lyer patterns. Parts of this research were presented at the 1985 and 1986 annual meetings of the Eastem Psychological Association. Correspondence concerning this article should be addressed to Patricia R. DeLucia, who is now at the Psychology Department, Texas Tech University, Lubbock, TX, 79409-2051.
Moreover, we have long had scattered evidence, and architects have long believed (Coren \& Girgus, 1978; Fletcher, 1905, cited in Fisher \& Lucas, 1969; Goodyear, 1899; Luckiesh, 1922; Pirenne, 1970), that illusions can occur with a freely moving observer in a normal spatial environment. For example, the Ponzo illusion is obtained in three-dimensional constructions (Brislin \& Keating, 1976; Leibowitz, Brislin, Perlmutter, \& Hennessy, 1969) and in binocular real-world views (Leibowitz et al., 1969); the Müller-Lyer illusion (Müller-Lyer, 1889/1981) occurs in three-dimensional constructions (DeLucia \& Hochberg, 1985, 1986; Massaro \& Anderson, 1970; Müller-Lyer, 1889/1981; Nijhawan, 1991; Zanforlin, 1967); the Hering illusion and subjective contours occur with wires and rods (DiLollo \& Marshall, 1969; Ware \& Kennedy, 1977); the vertical-horizontal illusion occurs with natural viewing conditions and familiar objects (Chapanis \& Mankin, 1967; Luckiesh, 1922).

Thus one cannot say that illusions occur only in twodimensional artificial displays, and illusions must therefore be taken into account in any general explanation of the perception of spatial layout and form. But it might still be true that these examples occur only in rare viewing situations that are too impoverished to engage the normal and veridical perceptual processes, which, it is argued, rest on full information (Gibson, 1950, 1966, 1979; Michaels \& Carello, 1981). The distinction between impoverished and adequate visual information is currently unspecified, however (see Cutting, 1986; Hochberg, 1981, 1982; Hochberg \& Smith, 1955); we simply do not know how rare such impoverishment is in the real world, which after all includes night driving (see Gogel \& Tietz, 1977; Owens \& Leibowitz, 1976), athletic tasks requiring extremely truncated viewing times, and expanses of smooth pavement and hidden horizons that deny us much in the way of potential visual information. At the very least, illusions should be important tools in the attempt 
to map the boundaries between adequate and impoverished information.

Unimpoverished perception has been characterized by free head and body movement by an active perceiver, as opposed to a fixed passive viewpoint, and by textured surfaces and backgrounds, as opposed to lines (or wires) in empty space (Gibson, 1966, pp. 199, 296, 313; 1979, pp. $2,3,25-28,159,168,281)$. We therefore used these conditions, as well as binocular vision and unfettered leisurely viewing, in most of the experiments we report here. Geometrical illusions were obtained nevertheless. At least these illusions, therefore, are relevant to theories of normal perception, and to any practical concerns about perceptual accuracy.

\section{EXPERIMENT 1}

Surface texture on the object being judged, and on the background against which its parts are seen, presumably offers the viewer invariant gradients of veridical information about the distances and loci within the layout. Without such texture, the viewing situation is said to be impoverished and unnatural, allowing illusions to occur because of insufficient information (Gibson, 1950, 1979; Michaels \& Carello, 1981). Our first step toward providing unimpoverished viewing was therefore to provide texture to both the target object and its background-that is, to measure the Ponzo illusion with a wooden stick-figure held against a surface whose texture varied from very impoverished (blank) to a full-cue environment.

\section{Method}

Subjects. Ten college students with normal or corrected visual acuity received all experimental conditions.

Stimuli. Three Ponzo patterns were constructed from wood strips (with grain exposed) glued to transparent sheets of glass $(21.6 \times$ $28 \mathrm{~cm})$. Figure 1 is a scale representation. The ratios of top to bottom strips in the three versions were $1.00, .897$, and .570 , respectively. Ground-plane or background surface information was manipulated by presenting the pattern directly against each of three controlled backgrounds, which varied in texture in specified ways, and also by holding the glass plate in front of an uncontrolled normally cluttered internal room environment. (The last cannot be further specified, in that it varied with each free shift in viewpoint, but we should note in advance that its effects did not differ from the others'.) The controlled backgrounds were the size of the glass plates; one was a solid white sheet, one was a random black-andwhite texture, and one was a blue-and-white grid-a sheet of graph paper (10 squares per inch).

Observers viewed each pattern binocularly from approximately $1.2 \mathrm{~m}$ with no constraints on mobility. In each case, they were to estimate the lengths of both wood strips to the nearest $1 / 8$ in. or to the nearest centimeter, whichever they preferred. The experimenter presented each pattern against each background, presented in the following order: white, grid, texture, room, room, texture, grid, white. Each observer completed a total of 48 trials, including 4 per stimulus $\times$ background combination ( 2 per strip).

\section{Results}

Figure 2 shows that we obtained an illusion close to that reported for line drawings on blank paper. When the top and bottom strips were actually equal, the perceived ratio was significantly greater than 1.00 for all backgrounds [smallest mean: $M=1.06, t(9)=3.38$; largest mean:

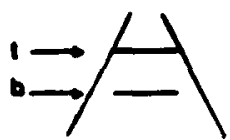

w

1.0

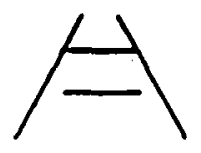

.

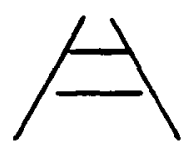

6
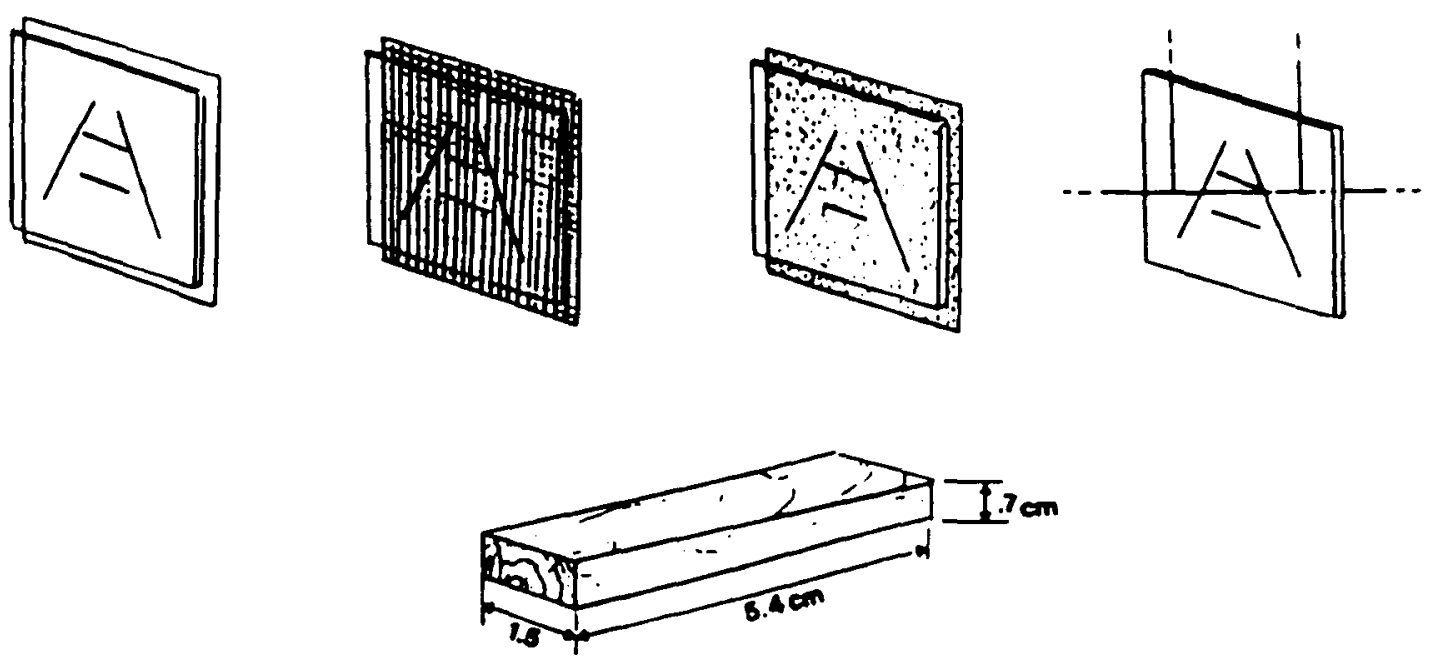

Figure 1. Experiment 1. Top: Representations of Ponzo patterns with three different ratios of top to bottom horizontal strips, and four different backgrounds. Bottom: Dimensions of wooden strips used to create the Ponzo figure. 


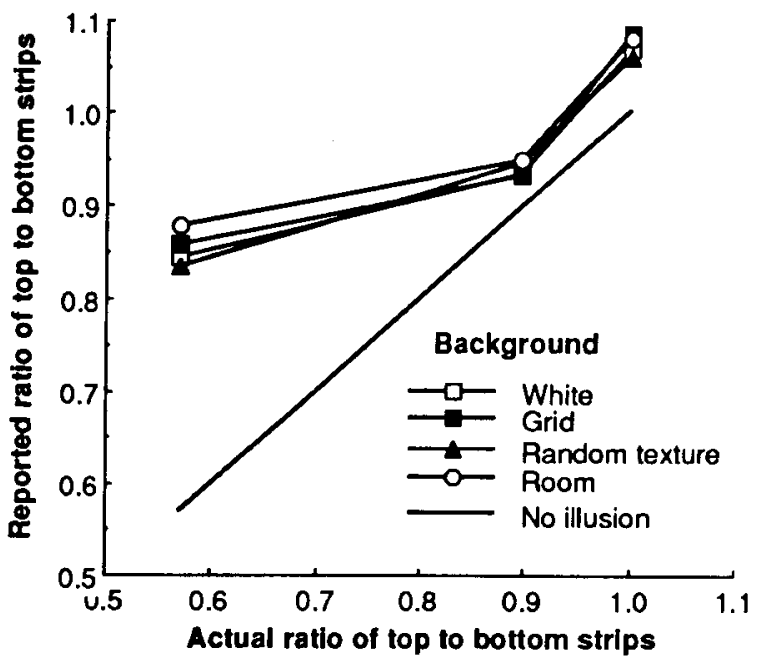

Figure 2. Experiment 1: Mean reported ratio of top to bottom strips for each stimulus ratio and backgrounds.

$M=1.08, t(9)=3.89 ; p<.01$ for all.$^{2}$ We converted each observer's mean perceived top-to-bottom ratio, or point of subjective equality (PSE) to a percent magnitude of illusion (e.g., Brunswik, 1956, p. 17; Dengler, 1972; Restle \& Decker, 1977). Except for the .897 ratio when the strips were held against the white background, percent illusion was significantly above zero for all ratios and backgrounds; for the .897 ratio when the patterns were held against the grid, $p<.05$; for all others, $p<.01$.

A $3 \times 4$ (ratio $\times$ background) analysis of variance (ANOVA) indicated a significant main effect of the length of the strips $\left[F(2,18)=147.09, p<.0001, \omega^{2}=\right.$ $78.5 \%$ (omega-squared or variance accounted for; Dodd \& Schultz, 1973)], but not of background; nor was there a significant interaction between them. Tukey's HSD tests (Howell, 1982) indicated significant differences between the .57 and .897 ratios $(p<.01)$ and between the .57 and 1.00 ratios $(p<.01)$, but not between the .897 and 1.00 ratios. The magnitude of illusion, when averaged across background, increased by a factor of at least six when the ratio of the horizontal strips decreased from .897 or 1.00 to .57 .

\section{Discussion}

The Ponzo illusion clearly occurs in free binocular viewing, regardless of the surface against which the pattern is held. However, even though the stimuli were normally textured wood strips, they were arguably line-like objects, laid out in a convergent pattern, and their threedimensional form was similar to their two-dimensional or projected shape. Furthermore, the viewer's response was passive in the sense that no interaction with the stimulus pattern was required.

Massaro and Anderson (1970) obtained the Müller-Lyer illusion by using folded flat trapezoidal cardboard cutouts, as well as stick figures. Again, one might argue that shapes delineated by the edges of flat sheets or by assembled sticks, viewed under impoverished conditions, are little more than line drawings. Moreover, as in our first experiment, subjects responded nonmanipulatively (by matching or marking off line lengths to indicate the apparent lengths of the central axes). In Experiment 2, we eliminated any converging line-like components and provided an active and manipulative (adjustment) method of measurement.

\section{EXPERIMENT 2}

In this experiment, we asked whether the optic array afforded by lines of sight tangent to the curving surfaces of a solid cone would provide the same illusion as would the drawings that would also fit the two-dimensional projections (in the visual field or retinal image) of those cones. The cones, if they are considered as distal volumetric objects whose three-dimensional layout is directly perceived by a free-viewing observer (Gibson, 1979), do not offer the converging perspective-like lines by which the Müller-Lyer illusion has been demonstrated and studied; such converging lines are in fact provided within the retinal images that the cones offer. With free, unimpoverished viewing, the optic array should specify only the surfaces' changing angles to the line of sight. As we will see, the illusion is nevertheless obtained with free and normal, unimpoverished viewing of such cone-shaped objects.

Even though illusions do then occur, they might be different ones, unrelated except by superficial chance resemblance to those that are manifest in line drawings; this would once again make the latter irrelevant to normal perceptual theory (Fisher \& Lucas, 1969, p. 13). We must consider not merely whether an illusion occurs during unimpoverished viewing, but whether it shows its characteristic magnitude as well; and in the case of the Müller-Lyer, we will measure how it varies with the angles between the shaft and fins, a factor that in line drawings (and in line-like objects: Massaro \& Anderson, 1970) is known to affect its magnitude. As we will see, simple and impoverished line drawings cannot be considered irrelevant to normal perception, inasmuch as they predict well the function of the illusion magnitude that is obtained with the three-dimensional cones.

\section{Method}

Subjects. Eight paid observers with normal or corrected vision.

Stimuli and Apparatus. Figure 3 shows a representation of the solid Müller-Lyer patterns used in this experiment. Three shafts were clear plastic dowels, approximately $44 \mathrm{~cm}$ in length, on each of which were mounted three clear, solid plastic cones to form three separate solid "Müller-Lyer objects." The cones offered $10^{\circ}, 50^{\circ}$, and $70^{\circ}$ angles to the shaft, respectively. Fin length was kept constant at $5.8 \mathrm{~cm}$, so that the horizontal length from the apex to the base of each cone (i.e., height) increased with a decrease in fin angle. This resulted in a slightly different point of objective equality (POE) for each set of cones, specifically $19.2,20.25$, and $21.1 \mathrm{~cm}$ for the $10^{\circ}, 50^{\circ}$, and $70^{\circ}$ stimuli, respectively. The two end cones were fixed, and the middle cone was moved.

Design and Procedure. All observers viewed each of the objects, one at a time, in a counterbalanced order $(50,70,10,70$, $50,10)$. The pattern was placed on a wooden rack about $.61 \mathrm{~m}$ in 


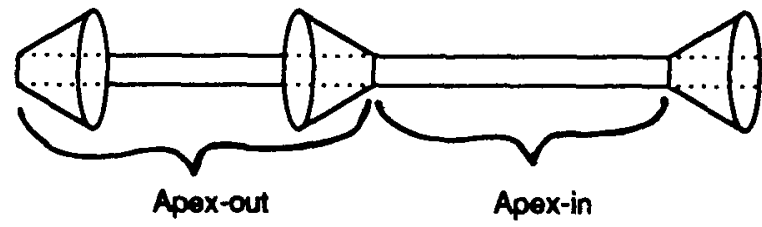

Figure 3. Experiment 2: Representation of a Müller-Lyer pattern made from solid clear cones.

front of the observers, who viewed it binocularly and were allowed free mobility of eyes, head, and body against the background of a normally cluttered room. They were instructed to move the middle cone to make the apex-out and apex-in distances (see Figure 3) appear equal, so that the perceptual behavior was active and manipulative (see Gibson, 1979, pp. 184, 224-226, 236-237, 245). The experimenter emphasized that judgments should be based on how the pattern appeared, rather than on irrelevant scratches or nicks on the shaft, cognitive strategies, or memory, and also that the viewer was free to move in any way desired. The apex-out distance was located to the right of the apex-in distance or vice versa to create two different orientations, which were counterbalanced across observers.

To control for effects of the initial position of the middle cone (previously reported by DeLucia \& Hochberg, 1985), this initial position was randomly varied. First, the middle cone was moved to one end to maximize the apex-in distance; this was $26.7,33.1$, or $38.1 \mathrm{~cm}$ for the three stimuli, respectively. These distances were then each divided into five equal segments, not including the POE. To replicate the 3.75 shaft-to-cone length ratio used by Heymans with line drawings (as given by Berliner, 1948), two more positions were added: apex-out and apex-in distances of $22 \mathrm{~cm}$. A total of 42 trials, 2 at each of the seven initial positions for each pattern, were completed by each observer. The constant error, or difference between PSE and POE (Engen, 1971, p. 13) was measured and expressed as a percent of POE.

\section{Results}

Data for Experiment 2 are graphed, together with those for Experiment 3, in Figure 4. The mean magnitude of illusion was significantly above zero for the $10^{\circ}[t(7)=$ $5.1, p<.002], 50^{\circ}[t(7)=6.7, p<.001]$, and $70^{\circ}$ $[t(7)=4.2, p<.005]$ angles and for all apex-in positions. As shown in Figure 4, the inverse relationship between magnitude of illusion and fin angle approximates that found by Heymans with line drawings (Berliner, 1948): as angle increased from $10^{\circ}$ to $50^{\circ}$ to $70^{\circ}$, the magnitude of illusion decreased from $16.1 \%$ to $12.3 \%$ to $8.3 \%$.

A $2 \times 3 \times 7$ ANOVA (orientation $\times$ angle $\times$ initial apexin position, with repeated measures on the last two factors) indicated significant effects of fin angle $[F(2,12)=$ $\left.19.93, p<.002, \omega^{2}=16.09 \%\right]$ and initial apex-in position $\left[\mathrm{F}(6,36)=3.76, p<.038, \omega^{2}=.67 \%\right]$, but no significant interactions. Tukey's HSD tests showed significant differences among all three angles $(p<.05)$, and among only 4 out of 21 possible pairs of initial positions.

\section{Discussion of Experiments 1 and 2}

Two of the major geometrical illusions therefore do $\propto c-$ cur with solid objects in normal and unimpoverished view- ing conditions, much as they occur with line drawings; at least, this is so if those objects are projectively similar to the line drawings whether the objects are themselves line-like (Experiment 1; Massaro \& Anderson, 1970) or consist of curved surfaces that fit the line drawings only by their silhouettes-that is, by the static projection of the lines of sight tangent to the surfaces (Experiment 2). However, one may argue that the objects used were too small for normal veridical perception, a point raised by Howard Flock at presentations of the earlier partial demonstrations (verbal communication, DeLucia \& Hochberg, 1985).

Against this argument, we note that architects have long felt that they must compensate for illusions in large structures, from the Parthenon of Athens to Low Library at Columbia University. ${ }^{3}$

In a formal experiment, Gehringer and Engel (1986) reported that although the magnitude of the Ames room illusion was substantially less with binocular, unrestrained viewing than in static monocular viewing, it was still significant, contrary to Gibson's assertion about it (1979, p. 168). But these demonstrations do not include the geometrical (line-drawing) illusions.

The next experiment was designed to determine whether the Müller-Lyer illusion occurred with active observers moving about much larger objects than those in Experiments 1 and 2.

\section{EXPERIMENT 3}

\section{Method}

Subjects. Eight paid observers with normal or corrected acuity, and with no prior experience with this type of experiment, received all experimental conditions.

Stimuli and Apparatus. A composite Müller-Lyer pattern without a connecting shaft was constructed from large pieces of plywood painted gray and placed in a large carpeted laboratory

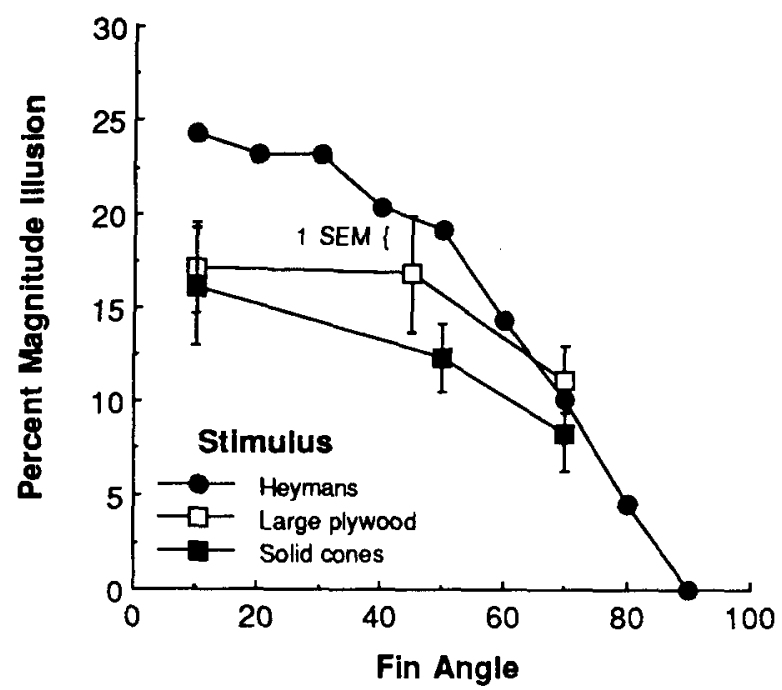

Figure 4. Experiments 2 and 3: Mean percent illusion as a function of fin angle averaged across other factors. Data from Heymans (Berliner, 1948) are also shown. Vertical bars indicate $\pm 1 S E$. 


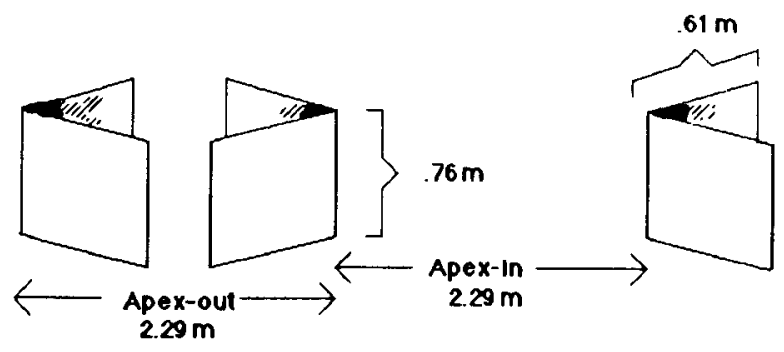

Figure 5. Experiment 3: Representation of a Müller-Lyer pattern without a connecting shaft, constructed from large pieces of plywood.

space. As is shown in Figure 5, each fin was about $.61 \mathrm{~m}$ wide and $.76 \mathrm{~m}$ high. The two fins that constituted each "arrowhead" were hinged together with large loose-leaf rings, permitting adjustment of fin angle, to form a $10^{\circ}, 45^{\circ}$, or $70^{\circ}$ angle with the imaginary shaft. Apex-in and apex-out distances were constant at $2.29 \mathrm{~m}$.

Design and Procedure. The observers were instructed to walk back and forth along the side of the configuration so that they could observe fully the floor between the apices, without occlusion by the construction. They were instructed to make judgments only when they could see the floor between the relevant fins. As in Experiment 2, the observers were active (but not manipulative). Judgments were to be based solely on appearance and not on calculations (e.g., counting steps), knowledge, marks on the floor, or memory.

First, the observers reported which of the two distances appeared longer, using a two-alternative forced choice. Then they were instructed to draw a vertical mark on a horizontal response line to represent the apparent relationship between the apex-in and apexout distances, similar to methods used by Greist-Bousquet and Schiffman (1981), and Warren and Bashford (1977).

Five different response line lengths were used, centered horizontally on standard $21.6 \times 27.9 \mathrm{~cm}$ sheets of paper, in the following randomly generated order: $2.6,15.3,5.1,20.4$, or $10.2 \mathrm{~cm}$. The observers used all five lines for one angle, before proceeding to the next angle. The side of the line that was "cut off" by the vertical mark (to represent apparent relative distances of the MüllerLyer pattern), the left-right orientation of the Müller-Lyer pattern, and the order of line length and fin angle were counterbalanced across observers and included in the ANOVA as one "group" factor.

\section{Results}

The results are summarized in Figure 4. All 8 observers $(p<.004)$ always chose the apex-in distance as longer on all angles. The magnitude of illusion was averaged across line length for each angle separately, with means significantly above zero for $10^{\circ}[t(7)=7.20, p<.001]$, $45^{\circ}[t(7)=3.1, p<.02]$, and $70^{\circ}[t(7)=6.23$, $p<.001$ ]. A $2 \times 3$ (group $\times$ angle, with repeated measures on angle) ANOVA indicated no significant effects. However, fin angle accounted for $8.93 \%$ of the variance, and the overall mean magnitude of illusion decreased from $17.1 \%$ to $16.8 \%$ to $11.2 \%$ when fin angle increased from $10^{\circ}$ to $45^{\circ}$ to $70^{\circ}$, respectively. ${ }^{4}$

\section{Discussion}

This experiment demonstrated that an illusion like the Müller-Lyer, with a mean strength over all angles of $15 \%$, occurred with observers moving about large objects. Although the effect of fin angle on illusion magnitude, as obtained with solid cones and line drawings, was not statistically significant here, the means were in the same direction, and fin angle accounted for $8.93 \%$ of the variance. Perhaps the fin angle effects were insignificant here because a single pair of the fins (i.e., one arrowhead) requires more glances to encompass, compared to the smaller patterns. Alternatively, the absence of a significant angle effect may not be due to size per se: the pattern was always set to POE, and the method of reproduction was used, whereas in Experiment 3, the initial configuration varied, and the method of adjustment was used.

In any case, the illusion was robust and of approximately the same magnitude in both experiments. The significance of these findings is that a viable theoretical or practical account of normal perception by ambulatory observers must now include the illusions. We therefore consider next the major theoretical explanations.

\section{PERSPECTIVE THEORIES}

An old and still a major theory of geometrical illusions, exemplified today primarily by Gregory's work (1963, 1966, 1970; see also Coren \& Girgus, 1978; Tolman \& Brunswik, 1935; Woodworth, 1938), holds that many illusions, and particularly the Müller-Lyer, result from mistaking converging lines for linear perspective. Perspective theory as stated would seem to predict no illusions with three-dimensional objects (Massaro \& Anderson, 1970; Zanforlin, 1967), however, and it seems particularly inapplicable to Experiment 2, because there were no twodimensional lines to be misinterpreted.

However, the projection of the objects used in Experiment 2 does provide a pattern of diagonal or oblique edges in the retinal image or visual field, and that pattern might somehow become a misinterpreted depth cue, bypassing the real depth information in a size/distance compensation. Gillam's orthogonalization theory (1978), which assumes that viewers rotate shapes toward $90^{\circ}$ but which makes no assumptions about depth cues, might also be applicable here. In the next two experiments, therefore, we eliminated diagonal edges; in Experiment 4, we used line stimuli; in Experiment 5, with the same subjects, we used solid objects.

\section{EXPERIMENT 4}

\section{Method}

Subjects. Eight observers participating with normal or corrected acuity received all experimental conditions.

Stimuli and Apparatus. A black-on-white line drawing of the composite Müller-Lyer figure, without a connecting shaft, was embedded in the configurations shown in Figures 6A and 6B. Apexin and apex-out distances were always equal at $5.1 \mathrm{~cm}$. The fins were $2 \mathrm{~cm}$ in length and would have made a $45^{\circ}$ angle to a connecting shaft, had there been one.

Design and Procedure. In Figure 6A, the fins were oriented so that they presented horizontal and vertical lines to the eye, and did not support the diagonals of perspective as in Figure 6B. Observers viewed each pattern laid out on a table, $.74 \mathrm{~m}$ high, from about 
Non-Diagonal Lines

A

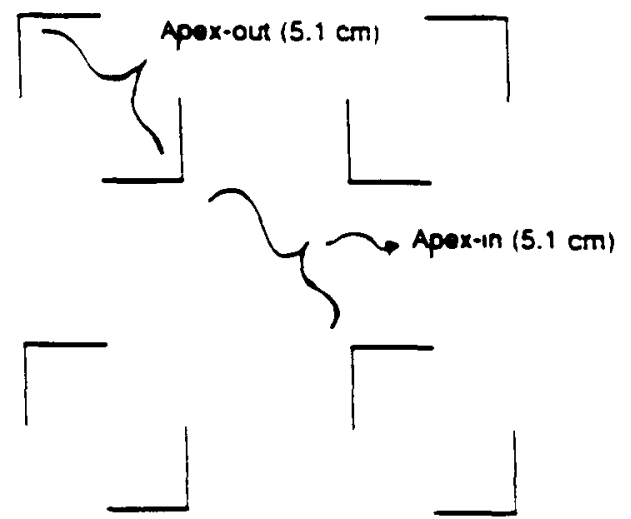

Diagonal Lines
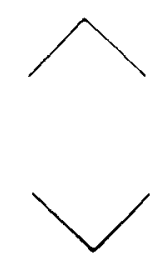

B
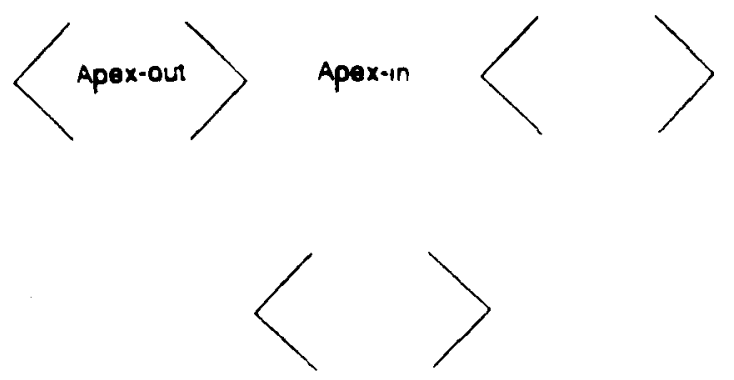

Figure 6. Experiment 4: Representation of a Müller-Lyer pattern embedded in a square configuration, with fins oriented to present nondiagonal (A) or diagonal (B) lines to the eye.

$.61 \mathrm{~m}$ away. The angle of regard varied with viewers' heights. Approximately as in Experiment 3, the subjects were to draw a vertical mark on a horizontal line with the left and right segments representing the apparent apex-out distance and apex-in distance, respectively. Figural orientation and line length were counterbalanced across subjects. Figure 6A preceded Figure 6B, which was a control to determine whether the traditional illusion occurred.

\section{Results}

The data from Experiments 4 and 5 are summarized in Figure 7. If the Müller-Lyer illusion depends on the misinterpretation of oblique lines offered by the fins, it should occur with Figure 6B, but not with Figure 6A. The perceived ratio of apex-out to apex-in lengths was much smaller than actual. The mean magnitudes of illu-

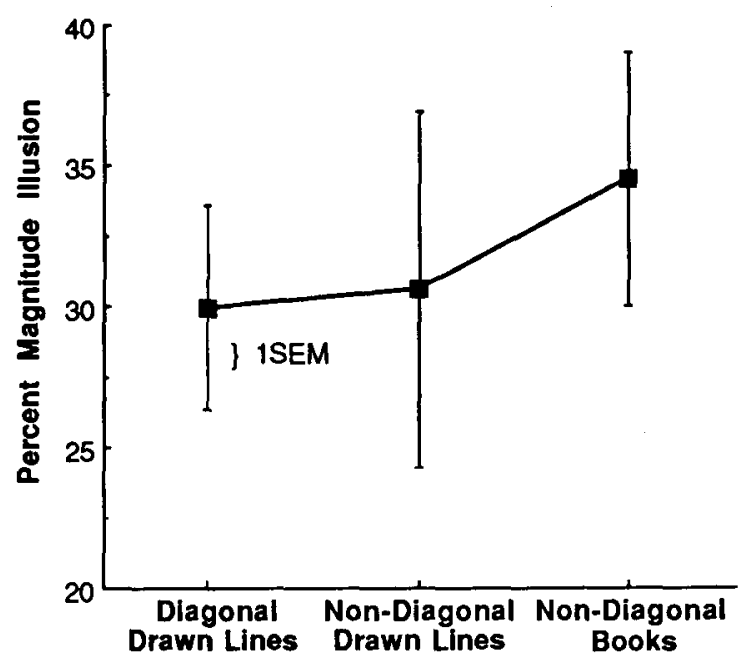

Figure 7. Mean percent illusion for line drawings in Experiment 4 and books in Experiment 5. Vertical bars indicaie $\pm 1 S E$. sion were about $31 \%$ and $30 \%$ for Figures $6 \mathrm{~A}$ and $6 \mathrm{~B}$, respectively $[t(7)=4.8, p<.002 ; t(7)=6.7, p<$ $.001]$, both significantly above zero; these magnitudes did not differ significantly.

As line drawings, Figure $6 \mathrm{~A}$ and $6 \mathrm{~B}$ are unnatural, abstract, and impoverished stimuli. In Experiment 5, a similar pattern, constructed from real, familiar threedimensional objects (small books) were arranged in the frontoparallel plane so that neither the distal nor proximal stimulus contained oblique lines.

\section{EXPERIMENT 5}

\section{Method}

Subjects. The observers were the same as those in Experiment 4; half of them completed Experiment 4 first, whereas half completed Experiment 5 first.

Stimuli and Apparatus. As represented in Figure 8, a composite Müller-Lyer pattern without a connecting shaft was constructed from three small identical books, $12 \mathrm{~cm}$ high and $8 \mathrm{~cm}$ wide, which were glued to plywood, $69 \mathrm{~cm}$ wide and $70.5 \mathrm{~cm}$ high. The book covers were open to $90^{\circ}$ (and therefore would form angles of $45^{\circ}$ to a connecting shaft, had there been one). The construction was frontoparallel to the observer, at about eye level when the observer was seated.

\section{Results}

The data are summarized in Figure 7. The perceived ratio of apex-out to apex-in lengths was again much smaller than actual. The mean magnitude illusion was about $35 \%[t(7)=9.6, p<.001]$. The data were analyzed with a $2 \times 2 \times 3$ ANOVA (orientation $\times$ experiment order $X$ stimulus, with repeated measures on stimulus; here stimulus refers to the magnitude of illusion from the line drawings in Experiment 4 and from the book pattern in Experiment 5). The analysis indicated only a significant interaction between stimulus and experiment order 


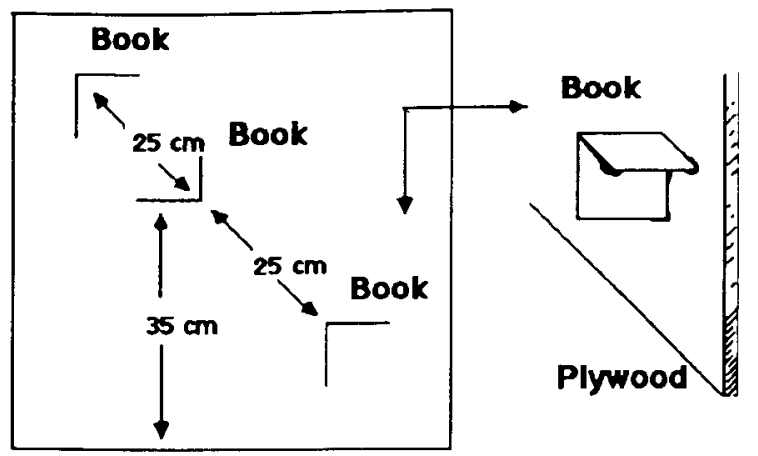

Figure 8. Experiment 5: Representation of a Müller-Lyer pattern constructed from small books and oriented to present nondiagonal lines to the eye.

$\left[F(2,8)=6.8, p<.051, \omega^{2}=24.39 \%\right]$. Simple main effect tests indicated an effect of stimulus $[F(2,16)=5.03$, $p<.025]$ only when the stimulus in Experiment 5 was viewed prior to the stimuli in Experiment 4. Tukey's HSD tests for subjects in that order indicated a significant difference only in the magnitude of the illusion between the book-configuration and Figure 6B from Experiment 4 $(p<.05)$; perhaps this was an order effect, since Figure 6B was always seen after Figure 6A. With no diagonal lines in either the distal or the proximal layout, it is hard to see how this illusion fits either a misapplied constancy theory or an orthogonalization theory as we understand them.

\section{CONCLUSIONS}

In Experiment 1, we showed that clearly coplanar bars with marked surface textures that were freely viewed against textured backgrounds yielded the Ponzo illusion appropriate to their configuration. In Experiment 2, objects made from solid cones that provided the Müller-Lyer pattern only as their static or momentary two-dimensional projections were presented for an active adjustment to apparent equality under free viewing conditions, and yielded illusions with the same parameters as the corresponding two-dimensional Müller-Lyer line drawings. In Experiment 3 , we found a similar illusion, using constructions made of large rectangular panels that were viewed by moving active observers. Those who wish to dismiss the geometrical illusions that have been demonstrated and studied with lines on paper as artifacts of two-dimensional stimuli and impoverished viewing conditions must somehow deal with these data, and with the others we have cited, if their contention is to be taken seriously.

At least some of the illusions occur in a wide range of conditions, including lines on paper and structures in the world. It is therefore important to predict their occurrence and magnitude. Prediction takes theory. Perspective theory, as presented to date, does not predict the outcome of any of these experiments, especially those in which no diagonals are used (Experiments 4 and 5), and or- thogonalization theory does not account for Experiment 5. Proponents of perspective or orthogonalization theories should deal with these data, and with those of Massaro and Anderson (1970), if their advocacy is to continue.

Of the major theories, there remains the class of "confusion" or "assimilation" theories, which we cannot rule out. According to these explanations (for reviews, see Coren \& Girgus, 1978, chap. 8, and Woodworth, 1938, chap. 25), observers respond not to the distance they are asked to judge, but to other dimensions of the figure instead. Although we did not test such theories directly, it should be noted that they are not explicitly addressed by any of our present data.

\section{REFERENCES}

BEATY, D. (1969). The human factor in aircrafi accidents. New York: Stein \& Day.

BerLiner, A. (1948). Lectures in visual psychology. Chicago: Chicago Professional Press.

Brislin, R. W., \& Keating, C. F. (1976). Cultural differences in the perception of a three-dimensional Ponzo illusion. Joumal of CrossCultural Psychology, 7, 397-411.

Brunswik, E. (1956). Perception and the representative design of psychological experiments (2nd ed.). Berkeley: University of California Press.

Chadwick, P. (1976). Visual illusions in geology. Science, 260, 397-401.

Chapanis, A., Mankin, D. A. (1967). The vertical-horizontal illusion in a visually-rich environment. Perception \& Psychophysics, 2, 249-255.

Coren, S., Gingus, J. (1978). Seeing is deceiving: The psychology of visual illusions. Hillsdale, NJ: Erlbaum.

Cutring, J. (1986). Perception with an eye for motion. Cambridge, MA: MIT Press.

DeLuCL, P. R. (1991). Pictorial and motion-based information for depth perception. Joumal of Experimental Psychology: Human Perception \& Performance, 17, 738-748.

Delucia, P. [R.], HochBerg, J. (1985). Illusions in the real world and in the mind's eye. Proceedings \& Abstracts of the Annual Meeting of the Eastern Psychological Association, 56, 38.

DeLuCta, P. [R.], HochBerg, J. (1986). Real-world geometrical illusions: Theoretical and practical implications. Proceedings \& Abstracts of the Annual Meeting of the Eastem Psychological Association, 57, 62.

DENGLER, M. (1972). A test of constancy scaling theory in a modified Mueller-Lyer illusion. Perception \& Psychophysics, 12, 339-341.

Di Lollo, V., \& Marshall, A. J. (1969). Illusion in a three-dimensional Hering figure in relation to viewing distance. Perception \& Psychophysics, 5, 53-55.

DodD, D. H., \& SCHultz, R. F., JR. (1973). Computational procedures for estimating magnitude of effect for some analysis of variance designs. Psychological Bulletin, 79, 391-395.

ENGEN, T. (1971). Psychophysics: I. Discrimination and detection. In J. W. Kling \& L. Riggs (Eds.), Woodworth and Schlosberg's Experimental psychology (pp. 11-46). New York: Holt, Rinehart \& Winston.

FISHER, G. H., LuCAS, A. (1969). Illusions in concrete situations: I. Introduction and demonstrations. Ergonomics, 12, 11-24.

Gehringer, W., ENGEL, E. (1986). Effect of ecological viewing conditions on the Ames distorted room illusion. Joumal of Experimental Psychology: Human Perception \& Performance, 12, 181-185.

Gibson, J. J. (1950). The perception of the visual world. Boston: Houghton-Mifflin.

GIBson, J. J. (1966). The senses considered as perceptual systems. Boston: Houghton-Mifflin.

GiBson, J. J. (1979). An ecological approach to visual perception. Boston: Houghton-Mifflin.

GiLLAM, B. (1978). A constancy-scaling theory of the Müller-Lyer 
illusion. In J. P. Sutcliffe (Ed.), Conceptual analysis and method in psychology: Essays in Honor of W. M. O'Neill (pp. 57-70). Sydney: Sydney University Press.

GiLunGHAM, K. K., \& WoLFE, J. W. (1985). Spatial orientation in flight. In R. L. DeHart (Ed.), Fundamentals of aerospace medicine (pp. 299381). Philadelphia: Lea \& Febiger.

Gogel, W. C., TIETZ, J. D. (1977). Eye fixation and attention as modifiers of perceived distance. Perceptual \& Motor Skills, 45, 343-362.

GoOdyeaR, W. H. (1899). Horizontal curves in Columbia University. Architectural Record, 9, 82-93.

Greenhouse, S. W., Geisser, S. (1959). On methods in the analysis of profile data. Psychometrika, 24, 95-112.

GReGoRY, R. L. (1963). Distortion of visual space as inappropriate constancy scaling. Nature, 199, 678-680.

Gregory, R. L. (1966). Visual illusions. In B. Foss (Ed.), New horizons in psychology. Baltimore: Penguin Books.

GrEGORY, R. (1970). The intelligent eye. London: Weidenfeld \& Nicolson.

Greist-Bousquet, S., \& SChiffman, H. (1981). The many illusions of the Müller-Lyer: Comparisons of the wings-in and wings-out illusions and manipulations of standard and dot forms. Perception, 10, 147-154.

HoCHBERG, J. (1981). Levels of perceptual organization. In M. Kubovy \& J. Pomerantz (Eds.), Perceptual organization (pp. 255-278). Hillsdale, NJ: Erlbaum.

Hochberg, J. (1982). How big is a stimulus? In J. Beck (Ed.), Organization and representation in perception (pp. 191-216). Hillsdale, NJ: Erlbaum.

HochBerG, J., SMITH, O. W. (1955). Landing strip markings and the "expansion pattern": I. Program, preliminary analysis, and apparatus. Perceptual \& Motor Skills, 2, 81-92.

Howel, D. (1982), Statistical methods for psychology. Boston: Duxbury Press.

ITrLEsoN, W. H. (1952). The Ames demonstrations in perception. Princeton: Princeton University Press.

Leibowitz, H., Brisun, R., Perluutter, L., \& Hennessy, R. (1969). Ponzo perspective illusion as a manifestation of space perception. Science, 166, 1174-1176.

LuckIzsh, M. (1922). Visual illusions: Their causes, characteristics, and applications. New York: Dover.

МАCK, E. (1897). Contributions to the analysis of the sensations (C. M. Williams, Trans.). La Salle, IL: Open Court.

Massaro, D., ANderson, N. (1970). A test of a perspective theory of geometrical illusions. American Joumal of Psychology, 83, 565-575.

Michaels, C., \& Carello, C. (1981). Direct perception. Englewood Cliffs, NJ: Prentice-Hall

Mú́lLER-LYER, F. C. (1889). Optische Urteilstäuschungen. Archiv fur Anatomie und Physiologie, Physiologische Abteilung 2 (Supplement), 263-270. (Translated by $R$. Day \& $H$. Knuth, The contributions of F. C. Müller-Lyer. Perception, 1981, 10, 126-146.)

Nuhawan, R. (1991). Three-dimensional Müller-Lyer illusion. Perception \& Psychophysics, 49, 333-341.

OWENs, D. A., LeIBOwItZ, H. W. (1976). Oculomotor adjustments in darkness and the specific distance tendency. Perception \& Psychophysics, 20, 2-9.

Pirenne, M. H. (1970). Optics, paintings, and photography. Cambridge, U.K.: Cambridge University Press.

Restle, F., Decker, J. (1977). Size of the Mueller-Lyer illusion as a function of its dimensions: Theory and data. Perception \& Psychophysics, 21, 489-503.

RoCk, I. (1973). Orientation and form. New York: Academic Press.
Tolman, E. C., Brunswrx, E. (1935). The organism and the causal texture of the environment. Psychological Review, 42, 43-77.

WARE, C., Kennedy, J. M. (1977). Illusory line linking rods. Perception, 6, 601-602.

WARREN, R. W., \& BASHFord, J. A. (1977). Müller-Lyer illusions: Their origin in processes facilitating object recognition. Perception, 6, 615-626.

WoODWORTH, R. S. (1938). Experimental psychology. New York: Holt.

ZANFortun, M. (1967). Some observations on Gregory's theory of perceptual illusions. Quarterly Joumal of Experimental Psychology, 14, 193-199.

\section{NOTES}

1. Fisher and Lucas $(1969$, p. 11) correctly cite Woodworth $(1938$, p. 650) as stating that "geometrical illusions are incidental to the perception of form." They therefore categorize Woodworth as a researcher who has "dismissed illusory distortions as greatly exaggerated in importance, with little, or no, relevance to the broader understanding of visual perception." However, Woodworth states that illusions occur not only in special figures of the laboratory, but in innumerable patterns and designs (p. 650), and that "illusions are more than mere curiosities, for they afford clues to the process of perception" (p. 643). Woodworth's use of the phrase "incidental to the perception of form" is clarified by the sentence that follows it: "They are errors in the apparent size and direction of parts of a figure resulting from the total impression of the figure" (p. 650).

2. All $t$ tests incorporate two-tailed probabilities. All $p$ values for the $F$ ratio reflect a Greenhouse-Geisser adjustment (1959; see also e.g., Howell, 1982, pp. 258, 371).

3. Vertical structures are inclined inward, horizontal structures are made convex upward, and vertical columns are made convex outward, to avoid the opposite appearances (Coren \& Girgus, 1978, pp. 4-7; Fletcher, 1905, cited in Fisher \& Lucas, 1969; Goodyear, 1899; Luckiesh, 1922, pp. 195-204). Borromini's arcade in Rome is reported to work like a real-world "Ames Room" (Ittleson, 1952), looking much longer than it really is, with corresponding size/distance consequences (Pirenne, 1970, pp. 152-153), and the Gateway Arch in St. Louis, Missouri shows a vertical-horizontal illusion, with its height appearing double its width, although both are equal (Coren \& Girgus, 1978, pp. 42, 44).

4. After this manuscript was submitted to press, Nijhawan (1991) independently also reported a decrease in illusion with a decrease in angle, using a different solid dihedral somewhat similar to that in our Experiment 3, and in DeLucia and Hochberg, 1985, 1986.

5. Present versions of perspective theory assume that the illusion represents a correction toward rectangularity, and the present stimuli are rectangular. One anonymous reviewer suggested that viewers recognized the Muiller-Lyer pattern despite its $45^{\circ}$ rotation, and that the memories thus elicited correspond to those that are responsible for the illusion according to perspective theory. This version of perspective theory, which is new to us, is not addressed by our present procedures and would need to be spelled out further before it could be tested: We should note that the $45^{\circ}$ rotation from diamond to square is thought to provide a massive, categorical change in appearance (see Mach, 1897; Rock, 1973); that the set of vanishing points implied by such perspective would be a highly unlikely one; and most important, that every angle of comer and edge that is found in the visual field should, by this reasoning, provide an implied perspective and associated illusions.

(Manuscript received March 20, 1991; revision accepted for publication July 30,1991 .) 